\title{
Rhabdomyolysis and acute renal failure after strenuous exercise and alcohol abuse: case report and literature review
}

\author{
Hospital Geral de Fortaleza, Fortaleza, Ceará, Brazil
}

\begin{abstract}
INTRDDUCTION
Rhabdomyolysis is a life-threatening condition in which skeletal muscle is damaged. There are numerous causes, and these include the use of drugs, muscle trauma, exposure to toxins, infections, hyperthermia, seizures and electrolyte abnormalities leading to cell lysis through ischemia and acidosis. ${ }^{1-4}$ Acute renal failure (ARF) due to rhabdomyolysis has been widely described in different clinical settings, and its main pathophysiological mechanisms are renal vasoconstriction, intraluminal cast formation and direct myoglobin toxicity. These have already been demonstrated in vitro. ${ }^{1,5}$ Rhabdomyolysis is an important cause of ARF and remains unrecognized in many cases. ${ }^{1,6,7}$ Around 33\% of the episodes of rhabdomyolysis lead to ARF. ${ }^{8}$ Strenuous exercise may lead to the disintegration of striated muscle, thereby resulting in the release of muscle cell constituents into the extracellular fluid and circulation. This may consequently cause pigment-nephropathy and ARF. 910
\end{abstract}

Many patients presenting with muscle swelling and compartment syndrome have their diagnosis confounded with deep vein thrombosis, thus delaying the correct treatment. ${ }^{11}$ The occurrence of muscle swelling and a history of alcohol misuse, drug overdose, traumatic muscle lesions and prolonged immobility or unconsciousness should raise the suspicion of rhabdomyolysis. ${ }^{11-13}$

The diagnosis is based on clinical features and laboratory findings such as urine stick reagents testing positive for blood in the absence of urinary erythrocytes; myoglobinuria and serum creatine kinase levels raised to more than five times the normal upper limit; high levels of lactate dehydrogenase, aspartate and alanine aminotransferases, phosphate and potassium; and initially low serum calcium concentration. ${ }^{7,11}$
The treatment should be instituted immediately, in order to prevent the factors that cause ARF, such as volume depletion, tubule obstruction, aciduria and free radical release. ${ }^{1}$ There is no specific treatment stated for rhabdomyolysis, but it is advised to give vigorous fluid replacement and sometimes administer mannitol to maintain adequate urine flow. Alkalization of urine by using sodium bicarbonate can reduce the risk of tubule obstruction by myoglobin casts. ${ }^{7}$ The prognosis may be excellent if the underlying mechanism of rhabdomyolysis can be identified and reversed, whenever this is possible.

After obtaining the patient's consent, we report on the case of a man who developed rhabdomyolysis after exhausting exercise followed by a heavy bout of drinking alcohol. $\mathrm{He}$ arrived at the emergency department with swollen legs and lower extremity compartment syndrome.

\section{CASE REPRRT}

A 39-year-old man had been practicing running four kilometers, using halfkilogram weights attached to each leg, on three days per week for 20 days. The day after the last race, he started to drink large quantities of red wine, continuing for two days. After this bout of drinking, he had a fight with his brother, who weighs $80 \mathrm{~kg}$. His brother fell on top of him, and he then lost consciousness for 10 hours, lying on a hard sofa. When he woke up, his legs were extremely painful, he could not walk, and he had a mild headache. According to his brother, he had a kind of seizure. The next day, he went to a small healthcare center, from which he received symptomatic medications, and then went back home.

A few hours later, he was admitted to the emergency room of the General Hospital of Fortaleza with painful, swollen,
- Elizabeth De Francesco Daher

- Geraldo Bezerra da Silva Júnior

Denise Menezes Brunetta

- Lícia Borges Pontes

- Glaydcianne Pinheiro Bezerra

\section{ABSTRACT}

CONTEXT: Rhabdomyolysis is a severe and lifethreatening condition in which skeletal muscle is damaged. Acute renal failure due to rhabdomyolysis has been widely described and its main pathophysiological mechanisms are renal vasoconstriction, intraluminal cast formation and direct myoglobin toxicity.

OBJECTIVE: To report on a case of acute renal failure (ARF) induced by rhabdomyolysis due to strenuous exercise and alcohol abuse and to describe the pathophysiology of this type of ARF.

CASE REPORT: A 39-year-old man arrived at the hospital emergency service with swollen legs and lower extremity compartment syndrome. $\mathrm{He}$ was oliguric and had serum creatinine and urea levels of $8.1 \mathrm{mg} / \mathrm{dl}$ and $195 \mathrm{mg} / \mathrm{dl}$, respectively. The diagnosis of rhabdomyolysis was made through clinical and laboratory findings (creatine kinase activity of 26320 IU/II). The initial treatment consisted of fluid replacement and forced diuresis. The specific treatment for compartment syndrome, such as fasciotomy, was avoided in order to prevent infection. Partial recovery of renal function was recorded, after ten hemodialysis sessions. Complete recovery was observed after two months of follow-up.

KEY WORDS: Rhabdomyolysis. Acute kidney failure. Compartment syndrome. Exercise. Alcoholic intoxication. 
tense and tender calves (Figure 1), and with signs of lower extremity compartment syndrome and oliguria-anuria, presenting with dark brown urine. No pulse could be felt in his feet. The physical examination also showed the presence of ecchymotic lesions on his left arm and buttock. Serum creatinine of $8.1 \mathrm{mg} / \mathrm{dl}$ and urea of 195 $\mathrm{mg} / \mathrm{dl}$ were recorded. Urinalysis using a dipstick was positive for red blood cells, white blood cells and proteins. Vigorous fluid replacement was undertaken, and forced diuresis was attempted through the administration of furosemide. His blood pressure was $160 / 100 \mathrm{mmHg}$, and antihypertensive therapy using nifedipine and captopril was administered. Rhabdomyolysis was suspected and a creatine kinase activity level of $26320 \mathrm{IU} / \mathrm{l}$ was found. The laboratory findings during his hospital stay are shown in Table 1. Acute renal failure was evident and hemodialysis was started. He was found to have a history of previ-

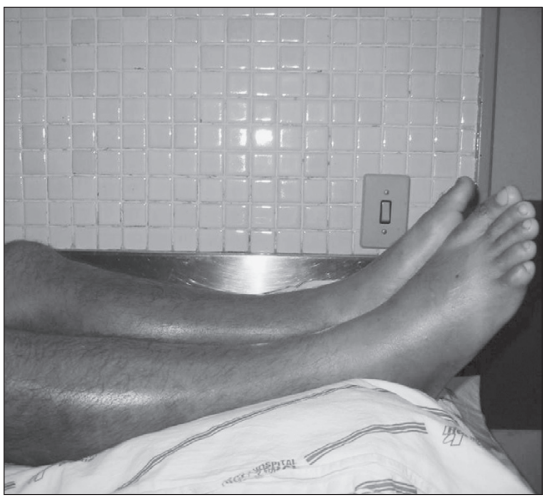

Figure 1. Patient's swollen legs, with tense calves at admission.

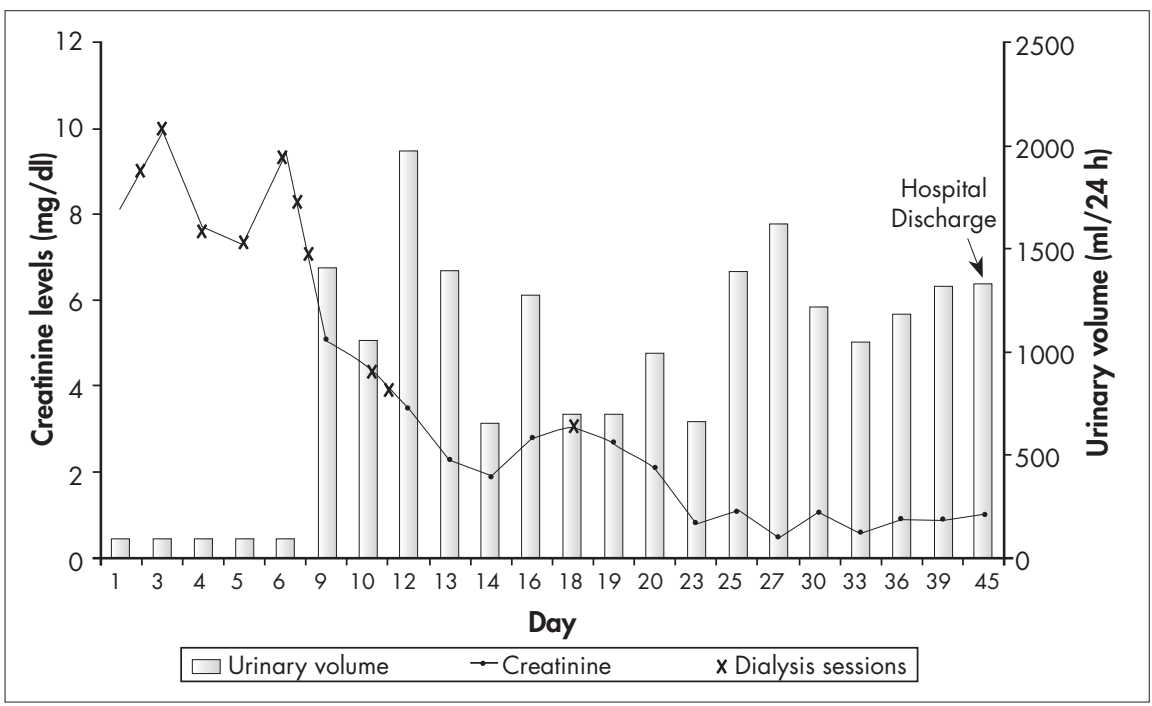

Figure 2. Urinary volume, serum creatinine levels and dialysis sessions during hospi-

talization, for a 39 year-old male patient with suspicion of rhabdomyolysis.

ous high blood pressure and alcohol and cocaine abuse.

On the seventh day of hospitalization, he presented with great pain and paresthesia in his feet. Physiotherapy was instituted in order to recover the movement in his legs. After ten sessions of hemodialysis, the urine volume started to increase, and the levels of urea and creatinine decreased to normal levels (Figure 2).

He was discharged from hospital after 45 days, still with painful legs and with difficulty in walking. At a follow-up evaluation, two months later, he presented with great improvement of the movement in his legs, and complete recovery of renal function was recorded.

Rhabdomyolysis is characterized by a broad spectrum of manifestations, ranging from a subclinical rise in creatine kinase to a medical emergency comprising interstitial and muscle cell edema, reduction in intravascular volume and pigment-induced acute renal failure. ${ }^{1}$ Myoglobinuria symptoms include muscle pain and weakness, pigmented urine and brown casts in tubules. ${ }^{5}$

After the occurrence of muscle damage, myoglobin is released into the circulation and is easily filtered by the glomeruli, with a depuration rate that corresponds to $75 \%$ of creatinine clearance. ${ }^{14}$ The serum levels of myoglobin can remain normal while urinary levels are high, because of this rapid filtration. There are two factors that predispose towards acute renal failure (ARF) due to rhabdomyolysis: hypovolemia secondary to liquid loss from damaged muscles and presence of acidic urine. ${ }^{14}$ In the absence of these events, myoglobin has a less nephrotoxic effect. ${ }^{6,14}$

The pathophysiology of myoglobinuric ARF has been extensively studied in an animal model of glycerol-induced ARF. ${ }^{1,6,15}$ The main mechanisms involved are renal vasoconstriction, intraluminal cast formation and direct heme protein-induced cytotoxicity. ${ }^{6,14}$ Renal vasoconstriction is favored by muscle necrosis, which leads to hypovolemia and the activation of cytokines. This increases capillary permeability and the binding of heme protein to nitric oxide: the endothelium relaxing factor. ${ }^{14}$ Casts are produced after the filtration of myoglobin through the glomerular basement membrane, which causes water reabsorption and a rise in myoglobin concentration. Following this, in the presence of acidic urine, myoglobin precipitation takes place and causes obstructive cast formation. ${ }^{1}$ Dehydration and renal vasoconstriction favor this process, through increased tubule reabsorption of sodium and water, which consequently increases myoglobin concentration in the tubules. ${ }^{14}$

Some studies have described the occurrence of dilation in the renal tubules, thus suggesting a high pressure in these compartments and contributing towards decreasing glomerular filtration. ${ }^{16,17}$ However, in the glycerol model of ARF due to rhabdomyolysis, it has been demonstrated that many tubules collapse and the mean intratubule pressure is below normal values. ${ }^{15}$ The high rates of generation and urinary excretion of uric acid further contribute towards tubule obstruction by uric acid casts. ${ }^{1}$

One additional factor that favors the precipitation of myoglobin and uric acid is low $\mathrm{pH}$ in the tubule urine, which is common because of underlying acidosis. ${ }^{1}$ It has been demonstrated that when urinary $\mathrm{pH}$ was kept at $8.0,78 \%$ of the myoglobin was excreted by the kidneys. ${ }^{6}$ Myoglobin can, through the heme fraction, induce the release of free iron, which catalyses free radical production and further enhances ischemic tubule damage. ${ }^{6,14}$ Alkaline conditions prevent this effect by stabilizing the reactive ferryl myoglobin complex. ${ }^{1}$ The heme fraction can also initiate lipid peroxidation and renal tubule injury. ${ }^{18}$ In an experimental study, the earliest renal changes caused by myoglobin were diminished by pyruvate-stimulated gluconeogen- 
esis, decreased total glutathione levels and induced lipid peroxidation. Pretreatment using reduced glutathione has provided complete protection of kidney slices from myoglobin toxicity. ${ }^{5}$

Another factor that could increase tubule obstruction is the possible occurrence of disseminated intravascular coagulopathy that has been described in rhabdomyolysis. ${ }^{7,19,20}$ This event causes the release of thromboplastin, leading to the production of microthrombus in the glomeruli and consequently decreased glomerular filtration. ${ }^{14}$

In the case presented here, we could see an elevated creatine kinase level and biochemical abnormalities such as raised levels of aspartate amino transaminase (AST) and alanine amino transaminase (ALT), lactate dehydrogenase, potassium and uric acid, accompanied by a low level of serum ionic calcium, as demonstrated in Table 1. These findings strongly suggest rhabdomyolysis. ${ }^{1,11}$ Our patient had his muscles damaged by different agents, including alcohol abuse and strenuous exercise. The fact that he was doing exercises using weights attached to his legs was crucial to the muscle injury.
The main muscles forced were those in the legs, which led to the development of lower extremity compartment syndrome.

Compartment syndrome is defined as a condition in which increased pressure within a limited space impairs capillary perfusion of the tissue within that space and can cause rhabdomyolysis. ${ }^{21}$ In the case presented here, the increase in compartment pressure seems to have been caused by the muscle injury, which led to edema formation and impairment of the normal circulation. The high pressure in his legs could be seen at admission through visible edema in his calves, which were stiff upon palpation (so-called doughy muscle), and severe pain.

Strenuous muscular exercise seems to play a decisive role in the pathogenesis of rhabdomyolysis, especially in untrained subjects or in individuals experiencing extremely hot or humid conditions. ${ }^{7,9,22}$ Among military recruits, intensive training in hot weather may predispose to exertion heat stroke and rhabdomyolysis. ${ }^{10}$ High temperatures are very relevant in the present case, because our city (Fortaleza) has very hot weather, with a mean annual temperature of $33^{\circ} \mathrm{C}$. Our patient had been running under such temperatures for several hours.

According to Vanholder et al., ${ }^{1}$ patients with acute or chronic alcohol intoxication have muscle dysfunction due to a combination of immobilization, hypokalemia, hypophosphatemia, agitation and direct myotoxicity of ethanol. Electrolyte abnormalities caused by alcohol ingestion are also important in muscle damage. Ethanol intoxication entails water-electrolyte and acid-base imbalance, in the form of metabolic acidosis, hypomagnesemia, hypocalcemia and hypophosphatemia. These are thought to take part in the mechanism for cell lysis. ${ }^{4}$ Alcohol has been associated with rhabdomyolysis in patients from Japan. All of these patients had been unconscious for several hours, and this contributed towards rhabdomyolysis through pressure necrosis, leading to acute renal failure in one of them. ${ }^{12,13}$ This could be observed in our patient, who had been drinking large amounts of alcohol for more than twenty years and had also undergone a heavy bout of drinking one day before the symptoms started, which led to unconsciousness for approximately 10 hours.

Table 1. Laboratory findings during hospitalization of a 39 year-old male patient with suspected rhabdomyolysis

\begin{tabular}{|c|c|c|c|c|c|c|c|c|c|c|c|c|c|c|c|}
\hline Day & 1 & 2 & 3 & 4 & 5 & 9 & 12 & 15 & 18 & 23 & 27 & 30 & 33 & 40 & 45 \\
\hline Urea (mg/dl) & 195 & 243 & 184 & 123 & 124 & 118 & 95 & 91 & 109 & 33 & 40 & 31 & 44 & - & 35 \\
\hline Creatinine $(\mathrm{mg} / \mathrm{dll})$ & 8.1 & 9.9 & 10.1 & 7.7 & 7.3 & 5.1 & 3.5 & 2.8 & 3.1 & 0.8 & 0.5 & 1.1 & 0.6 & - & 1.0 \\
\hline Potassium (mEq/l) & 4.9 & 7.6 & 5.5 & 4.4 & 4.3 & 4.0 & 4.7 & 4.6 & 4.6 & 4.8 & 4.7 & 4.2 & 6.4 & - & 4.4 \\
\hline Sodium (mEq/l) & 129 & 126 & 133 & 133 & 129 & 128 & 135 & 133 & 133 & 133 & 131 & 132 & 137 & - & 138 \\
\hline Ionic Calcium* & 1.03 & 0.90 & 1.06 & 1.14 & - & 1.38 & - & 1.36 & - & 1.25 & 1.28 & 1.34 & 1.18 & - & 1.32 \\
\hline Uric acid (mg/dl) & - & 12.5 & - & 7.7 & - & - & 6.5 & 5.5 & - & - & - & - & - & - & - \\
\hline Hematocrit (\%) & 32.5 & 30.5 & 26.9 & 24.8 & 20.2 & 19.9 & 18.9 & 22.8 & 20.9 & 27.1 & 26.6 & 26.6 & 27.6 & 34.0 & 30.3 \\
\hline Hemoglobin (g/dl) & 11.4 & 10.0 & 8.93 & 8.29 & 6.80 & 6.68 & 6.31 & 7.51 & 6.98 & 8.93 & 9.1 & 9.1 & 8.53 & 11.0 & 10.1 \\
\hline White blood cells $\left(\times 10^{3} / \mathrm{mm}^{3}\right)$ & 9.3 & 8.82 & 7.98 & 7.6 & 7.47 & 7.95 & 14.4 & 8.15 & 9.03 & 10.9 & 10.9 & 10.9 & 5.09 & 7.04 & 13.2 \\
\hline Platelets $\left(\times 10^{3} / \mathrm{mm}^{3}\right)$ & 148 & 136 & 133 & 145 & 152 & 271 & 132 & 112 & 128 & 339 & 438 & 438 & 382 & 371 & - \\
\hline Prothrombin time** & 11.0 & - & 12.5 & 12.4 & - & - & - & - & - & - & 14.6 & 13.9 & - & - & - \\
\hline Partial thromboplastin time*** & 28.1 & - & 36.9 & 52.2 & - & - & - & - & - & - & 22.6 & 31.7 & - & - & - \\
\hline AST (IU/I) & - & 730 & - & - & 293 & 75 & 38 & 67 & 67 & 74 & - & - & - & - & - \\
\hline ALT (IU/I) & - & 480 & - & - & 256 & 134 & - & - & - & - & - & - & - & - & - \\
\hline Direct bilirubin (mg/dl) & - & - & 0.07 & - & 0.20 & - & - & - & - & - & - & - & - & - & - \\
\hline Indirect bilirubin (mg/dl) & - & - & 0.59 & - & 0.98 & - & - & - & - & - & - & - & - & - & - \\
\hline LDH (IU/I) & - & 3280 & 3447 & - & - & - & 1065 & - & - & - & - & - & - & - & - \\
\hline CK (IU/I) & - & 26320 & 39420 & 20570 & - & 1740 & 653 & 202 & 202 & 105 & - & 149 & 125 & - & - \\
\hline Urine - Red blood cells & - & +++ & +++ & - & - & +++ & + & + & - & - & - & - & - & - & - \\
\hline White blood cells & - & +++ & +++ & - & - & +++ & +++ & ++ & - & - & - & - & - & - & - \\
\hline Protein & - & +++ & +++ & - & - & +++ & ++ & + & - & - & - & - & - & - & - \\
\hline
\end{tabular}

AST: aspartate amino transaminase; ALT: alanine amino transaminase; $L D H$ : lactate dehydrogenase; CK: creatine kinase

* normal ionic calcium levels: 1.12-1.32 mEq/l; ** control for prothrombin time = 13"; ${ }^{* *}$ control for partial thromboplastin time $=28$ " 
The patient said he had stopped using cocaine some months before this clinical event, but we must raise the suspicion of cocaine-induced rhabdomyolysis. In one study performed by Welch et al., ${ }^{23} 24 \%$ of cocaine users treated in the emergency room had rhabdomyolysis. Cocaine use was responsible for acute renal failure without rhabdomyolysis in one Spanish patient. ${ }^{24}$ The creatine kinase level of this patient was $107 \mathrm{UI} / \mathrm{l}$ and the only suggested cause of renal failure was the use of cocaine, through an underlying mechanism of intense vasoconstriction. Our patient used cocaine for eight years and could even have been still using it. However, it was not possible to assay the serum cocaine level to confirm our hypothesis of recent cocaine use. A wide spectrum of renal complications can occur with both acute and chronic use of this substance. Rhabdomyolysis is very common after cocaine use, because of prolonged vasoconstriction that causes muscle ischemia. ${ }^{25}$ Hypertension was found in our patient's history. Blood pressure frequently rises after using cocaine and this appears to contribute towards the development of ischemic renal failure. ${ }^{26,27}$

The diagnosis of rhabdomyolysis is achieved mainly through clinical features, including any history of strained exercise and alcohol use. The urine has a typical reddish-brown color, even in the absence of hematuria, and the main laboratory finding is an increased serum creatine kinase level. Rhabdomyolysis is easily confounded with deep vein thrombosis when the patient presents with acutely swollen and painful legs and an absence of pulse in the foot. ${ }^{11}$ All these were seen in our patient, but the history of running in an unusually forced manner and the episode of alcohol abuse lasting for two consecutive days made us think of rhabdomyolysis as the first diagnostic hypothesis. This was essential for the initial correct management of the patient, with the avoidance of the use of contrast media for diagnosing vessel obstruction, which would have caused even more renal damage.

No randomized trials for the management of rhabdomyolysis have yet been conducted, but there is a consensus for the administration of intravascular volume expansion by using saline solution and mannitol, to maintain urine output at more than $200-300 \mathrm{ml} /$ hour. $^{7}$ Alkalization of urine can be done in order to reduce the formation of myoglobin casts in renal tubules. ${ }^{7}$ Homsi et al. ${ }^{28}$ in a retrospective study, showed that progression to established renal failure following rhabdomyolysis could be totally avoided with prophylactic treatment in which volume repletion was achieved using saline alone, and the use of bicarbonate and mannitol was unnecessary. The treatment administered to our patient consisted initially of vigorous fluid replacement and forced diuresis using furosemide. The urea and creatinine levels were increasing, and therefore dialysis treatment was necessary. After ten hemodialysis sessions, his renal function had been restored, and this could be confirmed by the decrease in serum creatinine and the normal diuresis.

Specific treatment for compartment syndrome by means of fasciotomy is controversial. Some physicians advise surgical intervention, through immediate decompression of the muscles, thereby decreasing the pressure. However this creates a potential source of infection. ${ }^{1,29}$ In our case, fasciotomy was avoided and conservative therapy was instituted. Such a choice was deemed successful by Robinson et al., ${ }^{30}$ who studied six athletes with high compartment pressure. They were simply monitored in the hospital for muscle necrosis and acute renal failure. All these patients recovered completely.

In summary, the rhabdomyolysis described here was caused by different factors that had a cumulative effect and all contributed towards the development of acute renal failure. The diagnosis was achieved through clinical evidence and laboratory findings and the administration of contrast media was avoided in order to protect his kidneys. Fasciotomy was not performed, because it could have created a potential source of infection. Hemodialysis was the key component of the treatment and complete recovery of renal function was recorded two months after hospital discharge.
1. Vanholder R, Sever MS, Erek E, Lameire N. Rhabdomyolysis. J Am Soc Nephrol. 2000;1 1(8):1553-61.

2. Haas CE, Magram Y, Mishra A. Rhabdomyolysis and acute renal failure following an ethanol and diphenhydramine overdose. Ann Pharmacother. 2003;37(4):538-42.

3. Moore KP, Holt SG, Patel RP, et al. A causative role for redox cycling of myoglobin and its inhibition by alkalinization in the pathogenesis and treatment of rhabdomyolysis-induced renal failure. J Biol Chem. 1998;273(48):31731-7.

4. Sulowicz W, Walatek B, Sydor A, et al. Acute renal failure in patients with rhabdomyolysis. Med Sci Monit. 2002;8(1):CR24-7.

5. Minigh JL, Valentovic MA. Characterization of myoglobin toxicity in renal cortical slices from Fischer 344 rats. Toxicology. 2003;184(2-3):113-23.

6. Zager RA. Rhabdomyolysis and myohemoglobinuric acute renal failure. Kidney Int. 1996;49(2):314-26.

7. Lane R, Phillips M. Rhabdomyolysis. BMJ. 2003;327(7407):115-6.

8. Gabow PA, Kaehny WD, Kelleher SP. The spectrum of rhabdomyolysis. Medicine (Baltimore). 1982;61(3):141-52.
9. Schwaber MJ, Liss HP, Steiner I, Brezis M. Hazard of sauna after strenuous exercise. Ann Intern Med. 1994;120(5):441-2.

10. Yu FC, Lu KC, Lin SH, et al. Energy metabolism in exertional heat stroke with acute renal failure. Nephrol Dial Transplant. 1997;12(10):2087-92.

11. Mallinson RH, Goldsmith DJ, Higgins RM, Venning MC, Ackrill P. Acute swollen legs due to rhabdomyolysis: initial management as deep vein thrombosis may lead to acute renal failure. BMJ. 1994;309(6965):1361-2.

12. Sakamoto K, Ohata M, Hashimoto K, et al. [Two cases of alcoholics associated with rhabdomyolysis and acute renal failure]. Nihon Arukoru Yakubutsu Igakkai Zasshi. 2002;37(5):505-12.

13. Suzuki S, Nonaka A, Kumazawa T. [Compartment syndrome in a young male caused by acute alcoholic rhabdomyolysis]. Masui. 2002;51(10):1127-8.

14 Daher EF, Cordeiro NF. Acute renal failure due to rhabdomyolysis. Rev Bras Med. 1998;55(7):526-33.

15. Oken DE, Arce ML, Wilson DR. Glycerol-induced hemoglobinuric acute renal failure in rat. I. Micropuncture study of the development oliguria. J Clin Invest. 1966;45(5):724-35.
16. Baker SL, Doods EC. Obstruction of the renal tubules during the excretion of haemoglobin. Br J Exp Pathol. 1925;6:246-60

17. Oliver J, MacDowell M, Tracy A. The pathogenesis of acute renal failure associated with traumatic and toxic injury; renal ischemia, nephrotoxic damage, and the ischemic episode. J Clin Invest. 1951;30(12:1):1307-439.

18. Holt S, Moore K. Pathogenesis of renal failure in rhabdomyolysis: the role of myoglobin. Exp Nephrol. $2000 ; 8(2): 72-6$

19. Knochel JP. Rhabdomyolysis and myoglobinuria. In: Suki WN, Eknoyan G, editors. The kidney in systemic diseases. New York: John Wiley; 1981. p.263-84

20. Better OS, Stein JH. Early management of shock and prophylaxis of acute renal failure in traumatic rhabdomyolysis. N Engl J Med. 1990;322(12):825-9.

21. Bocca G, van Moorselaar JA, Feitz WFJ, van der Staak FH, Monnens LA. Compartment syndrome, rhabdomyolysis and risk of acute renal failure as complications of the lithotomy position. J Nephrol. 2002;15(2):183-5. 
22. Knochel JP. Catastrophic medical events with exhaustive exercise: "white collar rhabdomyolysis". Kidney Int. 1990;38(4):709-19.

23. Welch RD, Todd K, Krause GS. Incidence of cocaine-associated rhabdomyolysis. Ann Emerg Med. 1991;20(2):154-7.

24. Amoedo ML, Craver L, Marco MP, Fernández E. Cocaineinduced acute renal failure without rhabdomyolysis. Nephrol Dial Transplant. 1999;14(12):2970-1.

25. Crowe AV, Howse M, Bell GM, Henry JA. Substance abuse and the kidney. QJM. 2000;93(3):147-52.
26. van der Woude FJ. Cocaine use and kidney damage. Nephrol Dial Transplant. 2000;15(3):299-301.

27. Ahijado F, Garcia de Vinuesa S, Luño J. Acute renal failure and rhabdomyolysis following cocaine abuse. Nephron. 1990;54(3):268.

28. Homsi E, Barreiro MF, Orlando JM, Higa EM. Prophylaxis of acute renal failure in patients with rhabdomyolysis. Ren Fail. 1997;19(2):283-8.

29. Swain R, Ross D. Lower extremity compartment syndrome. When to suspect acute or chronic pressure buildup. Postgrad Med. 1999;105(3):159-62, 165, 168.
30. Robinson D, On E, Halperin N. Anterior compartment syndrome of the thigh in athletes--indications for conservative treatment. J Trauma. 1992;32(2):183-6.

Acknowledgments: The authors are very grateful to the eam of physicians, residents and nurses from the General for this patient.

Sources of funding: Not declared

Conflict of interest: Not declare

Date of first submission: March 8, 2004

Last received: July 30,2004

Accepted: August 10, 2004

\section{AUTHDRS INFDRMATIDN}

Elizabeth De Francesco Daher, MD, PhD. Doctorate in Nephrology from the Universidade de São Paulo; adjunct professor of the Discipline of Nephrology, Department of Clinical Medicine, School of Medicine, Universidade Federal do Ceará, Fortaleza, Ceará, Brazil.

Geraldo Bezerra da Silva Júnior. Sixth-year student, School of Medicine, Universidade Federal do Ceará, Fortaleza, Ceará, Brazil.

Denise Menezes Brunetta. Internal Medicine resident, School of Medicine of Ribeirão Preto, Universidade de São Paulo, Ribeirão Preto, São Paulo, Brazil.

Lícia Borges Pontes. Sixth-year student, School of Medicine, Universidade Federal do Ceará, Fortaleza, Ceará, Brazil

Glaydcianne Pinheiro Bezerra. Sixth-year student, School of Medicine, Universidade Federal do Ceará, Fortaleza, Ceará, Brazil.

Address for correspondence:

Elizabeth De Francesco Daher

R. Vicente Linhares, 1198

Fortaleza/CE - Brasil - CEP 60270-135

Tel./Fax (+55 85) 224-9725 - (+55 85) 261-3777

E-mail: efdaher@for.terra.com.br

E-mail: geraldobezerraj@@hotmail.com

Copyright () 2005, Associação Paulista de Medicina
RESUMD

Rabdomiólise e insuficiência renal aguda após exerć́cio intenso e abuso de álcool: Relato de caso e revisão da literatura

CONTEXTO: Rabdomiólise é uma condição clínica severa e ameaçadora à vida, em que ocorre destruição de músculo esquelético. Insuficiência renal aguda por rabdomiólise já foi bem descrita, sendo os principais mecanismos fisiopatológicos vasoconstrição renal, formação de depósitos intratubulares e toxicidade direta da mioglobina.

TIPO DE ESTUDO: Relato de caso e revisão da literatura.

OBJETIVO: Relatar um caso de insuficiência renal aguda (IRA) induzida por rabdomiólise devida a exercícios físicos intensos e uso abusivo de álcool e descrever os principais mecanismos fisiopatológicos deste tipo de IRA.

RELATO DE CASO: Homem de 39 anos foi admitido na emergência com edema e síndrome compartimental em membros inferiores. Ele estava oligúrico, e os níveis séricos de creatinina e uréia eram de $8,1 \mathrm{mg} / \mathrm{dl}$ e $195 \mathrm{mg} / \mathrm{dl}$, respectivamente. O diagnóstico de rabdomiólise foi obtido através dos dados da história clínica e dos exames laboratoriais (creatinoquinase de $26320 \mathrm{UI} / \mathrm{I}$ ). $\mathrm{O}$ tratamento inicial consistiu em reposição volêmica e diurese forçada. Tratamento específico para síndrome compartimental, como fasciotomia, não foi realizado para que se evitasse a ocorrência de infecções. Recuperação parcial da função renal foi observada após 10 sessões de hemodiálise. Recuperação completa ocorreu após dois meses de acompanhamento.

PALAVRAS-CHAVE: Rabdomiólise. Insuficiência renal aguda. Síndromes de compartimento. Exercícios. Intoxicação por álcool. 